\title{
Flexible Mathematical Understanding in an Ironworking Apprenticeship Classroom
}

\author{
LYNDON MARTIN, LIONEL LaCROIX and \\ LYNDA FOWNES
}

\begin{abstract}
The relationship between learning and context has long been an issue of interest and concern in the field of adult mathematics education. In particular, the questions of whether and how learning can be transferred from one context to another, remains a focus of researchers (Lave 1988, Lerman 1999, Evans 2000, Carraher and Scheliemann 2002). In this paper we look at the mathematical understanding of a group of apprentice ironworkers working on a construction task, and explore the flexible nature of their understanding. We consider the ways in which they are able to use quite formal mathematical ideas and operations and make sense of these within the specific context of their trade. Then we discuss how this process is more than one of simple transfer.
\end{abstract}

\section{Mathematical understanding in workplace training}

In workplace training, mathematical concepts are generally engaged with within a 'task context' (Wedege 2002:70), where the production of a performative solution is required; for example, that of producing a cut length of pipe to meet given specifications. To be able to learn and apply appropriate mathematics and perform the relevant calculations is something of a secondary aim. What matters in the workplace is the resultant product of the mathematics. Even in cases where mathematical ideas are introduced without the context of a particular task, they are usually framed in terms of the specific trade, for example; a worksheet might be titled 'Mathematics for plumbers' and include mathematical ideas specifically relevant to plumbing.

This is in contrast to the purpose of mathematical problem-solving as posed in the school classroom. Here, the focus is more likely to be the development of mathematical concepts, with the problem merely providing a context for this to occur (see Wedege 2002). Further, the solution to the problem would likely be a calculated answer, rather than an artefact; for example, a piece of pipe suitable for the task in hand. As Nunes, Schliemann and Carraher (1993:74) note 'school mathematics is learned mostly as written mathematics. Representations of the situation are abandoned as much as possible for the sake of generality. In consequence, mathematical 
relations represented in school mathematics have poor ties with problem situations'.

Mathematics in the workplace-training situation is generally engaged with as an integral part of the practices and demands of a specific trade. As a result, what it means to understand and use mathematics becomes more complex in this environment. Thus, in workplace training, it is insufficient to merely talk about the understanding of a particular mathematical concept without considering how such understanding is appropriate to and useable for real workplace tasks. In workplace training there are situated forms of mathematical understandings at play, which are a consequence of the need for mathematics to serve a purpose, to complete a task, or to produce a physical output. Pozzi, Noss and Hoyles (1998:117), in their study of the use of mathematics by nurses, stated that 'from our point of view as researchers, the question is not: "Do these nurses understand sufficient mathematics?" but rather "How do they make sense of the ways a tool represents a patient's state or outputs the correct data?" '. In a similar way, our question becomes 'How does their mathematical understanding enable apprentice ironworkers to complete a specific task?'

Nunes, Schliemann and Carraher (1993), in considering the approaches to a task by apprentice and master carpenters state:

mathematical problem solving involves the use of two types of representation $(a)$ representation of the problem situation and $(b)$ representation of mathematical relations. A good problem solver must be able to connect the two types of representation quite easily, pulling out the mathematical relations from a problem but also turning the mathematical relations around in ways not suggested by the meanings in the problem situation (74).

Like Nunes, Schliemann and Carraher (1993), our work recognises the vital importance of a workplace apprentice being able to make sense of the problem, being able to pull out the mathematical relations, and then being able to work with this mathematics with understanding. However, we prefer to use the term 'task' rather than 'problem' as this more closely describes the nature of workplace actions. We also introduce a third element into the process, that of understanding the specific mathematical practices of the particular trade, of knowing how things might actually be done on the job, and what this implies for the use of mathematics.

We are suggesting that mathematical understandings in the workplace can take a variety of forms, and that there is a range of ways of acting mathematically while working on a task. We continue to acknowledge the importance of formal mathematical ideas and operations, what Wedege 
(2002) terms 'school mathematics (what people learn and practice in formal education)' (71), and in this paper we illustrate how a group of ironworkers understand and work with such ideas. However, following Noss, Hoyles and Pozzi (2000), we suggest that alongside such images, other images or ways of acting mathematically, can also be observed and these are vitally important for contextualising the formal mathematics. These images are embedded in either the nature of the specific problem and its representation or, and of particular importance in this paper, in the particular local practices of the trade. This third kind of image or representation is something different from those offered by Nunes, Schliemann and Carraher (1993), as it involves understanding mathematics in a way that makes sense for the task or problem in the real life 'situation context' (Wedege 2002:64). Understanding mathematics in this way can involve a number of elements. These include, recognising what is 'usual' in the workplace, being familiar with quick ways of doing specific calculations, being aware of how calculated answers are appropriate to the actual task, and knowing what constraints the carrying out of the task might put on the mathematics. For example, in ironwork, after calculating the size of the choker needed to lift some assembled beams into place, it is common practice to always go up a size - for safety purposes and to allow for extra stresses in the lifting of the piece. Thus, not only is there the need to be able to calculate the size of choker required, but it is also necessary to know that this is actually a minimum specification. In such a case the 'correct' answer is both the one that is calculated and the one that is found by moving up a size from this. However, only one is actually useable in completing the task.

We do not see these three ways of understanding as being alternatives or incompatible with one another. Instead we suggest that apprentices are likely to engage with these different kinds of understandings many times as they progress through their training. In conceptualising understanding, and its growth as a multi-faceted and emergent phenomenon, we are influenced by the work of Pirie and Kieren (see for example Pirie and Kieren 1994, Kieren, Pirie and Gordon-Calvert 1999) and their theory for the dynamical growth of mathematical understanding which characterises 'mathematical understanding not as a product of actions but in terms of the actions themselves' (Kieren, Pirie and Gordon-Calvert 1999:212). In particular, and of significant relevance to this paper, is the notion that:

growth in understanding is not simply a matter of acting in more abstract ways with more and more abstract mathematical objects. Such growth in fact entails a dynamic and a connection between more and less formal, abstract and sophisticated activities. Because such growth in understanding occurs in contexts, a study of the growth of understanding must 
necessarily take into account the interactions that a person has with and in such contexts, including interactions with materials, other students and teachers. (Kieren, Pirie and Gordon-Calvert 1999:229)

In this paper, we focus on one group of apprentice ironworkers and explore the ways in which they draw on and work with these three different forms of mathematical understandings as they successfully complete a challenging construction problem: understandings of the task as posed; understandings of the mathematical relations required by the task; and understandings of the task as an actual job to carry out. We contend that it is the way that these apprentices are able to build an understanding that shifts and builds connections across these three dimensions, that leads to their success with the task.

\section{The group and task: planning the assembly of a building}

The larger study, of which this research forms a part, is made up of a series of case studies of apprentices training towards qualifications in various construction trades in British Columbia, Canada. The case studies involved video recorded observations, together with field notes and interviews with selected apprentices. Data were collected in the training classroom and workshop. Both whole classes and smaller groups of learners were observed, depending on the structure of the session. In observing and analysing the ways in which the apprentices used their mathematical knowledge in the context of workplace tasks we drew on elements of the Pirie-Kieren Theory for the dynamic growth of mathematical understanding.

This paper presents some initial findings and discussion drawn from one of these case studies, with a particular focus on identifying the mathematical images held, accessed, made, modified and worked with by three apprentices Although our conclusions are specific to this case, we would suggest that there are implications that may be relevant to the wider field.

The three apprentices discussed in this paper, and known as Joe, Andy and Mike, are in a larger class of about 20 students who are in the second year of an apprenticeship training program to become credentialed ironworkers. The course is part time, and consists of an initial six months at an institute of technology in Vancouver, BC, Canada, followed by four years in the workplace interspersed with three further six week block release sessions back at the institute

In this session the apprentices have been posed the task of establishing the size of a choker sling required to lift an assembled structure of four large iron beams into an upright position, and later of determining where the 
crane should be positioned to accomplish this. Figure 1 illustrates this as an actual event. The structure consists of two upright beams, one top crosspiece and one middle beam. As can be seen in the photograph, this structure is lifted into position using two chokers in a sling arrangement around the top beam. It is the size of these chokers that the apprentices have been asked to calculate, something that is dependant on the total weight of the structure to be lifted.

Although Figure 1 shows the final result of the task, that is, the practical act of the beam being lifted, the session discussed here was classroom based and involved the apprentices working with technical plans to determine the appropriate configuration prior to its practical implementation. At no time in this session were the apprentices involved in actually working with or lifting beams. It was a 'pencil and paper' exercise, but an essential one that would have to be completed on any worksite prior to the job being carried out. The apprentices, Joe, Andy and Mike, worked closely together for about one hour at a table where they were video and audio recorded.

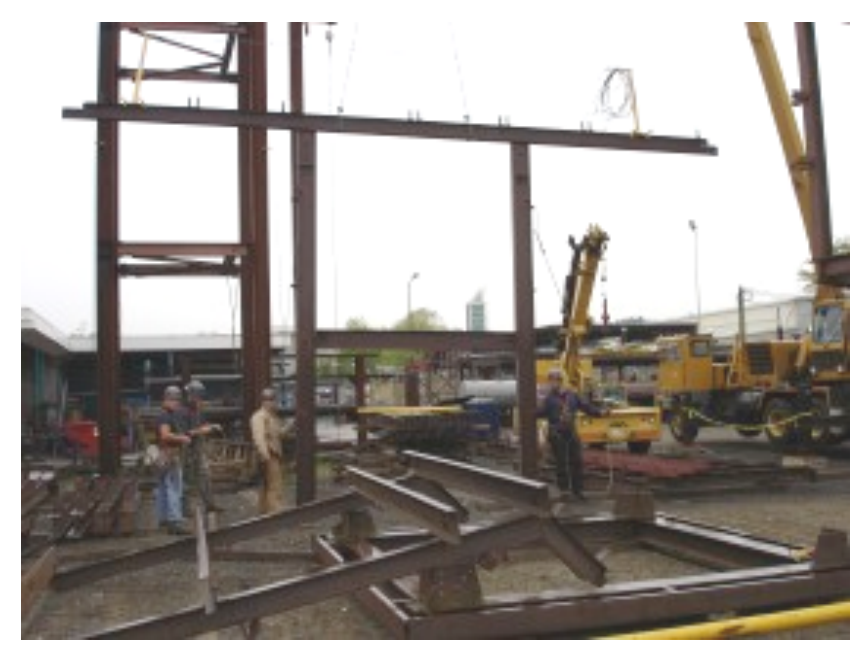

\section{Figure 1: The four beams, assembled and being lifted by a two-choker sling}

The apprentices are required to work with a set of eight technical plans, showing different elevations and views of the framework for the building. The plans contain all the information necessary to assemble the framework, but the form in which this is presented requires considerable extraction from, and interpretation of, the various diagrams. Figure 2 is one of the plans from which the group often work. It is not necessary to be able 
to read the diagram here, it is provided merely to illustrate the complexity of such plans.

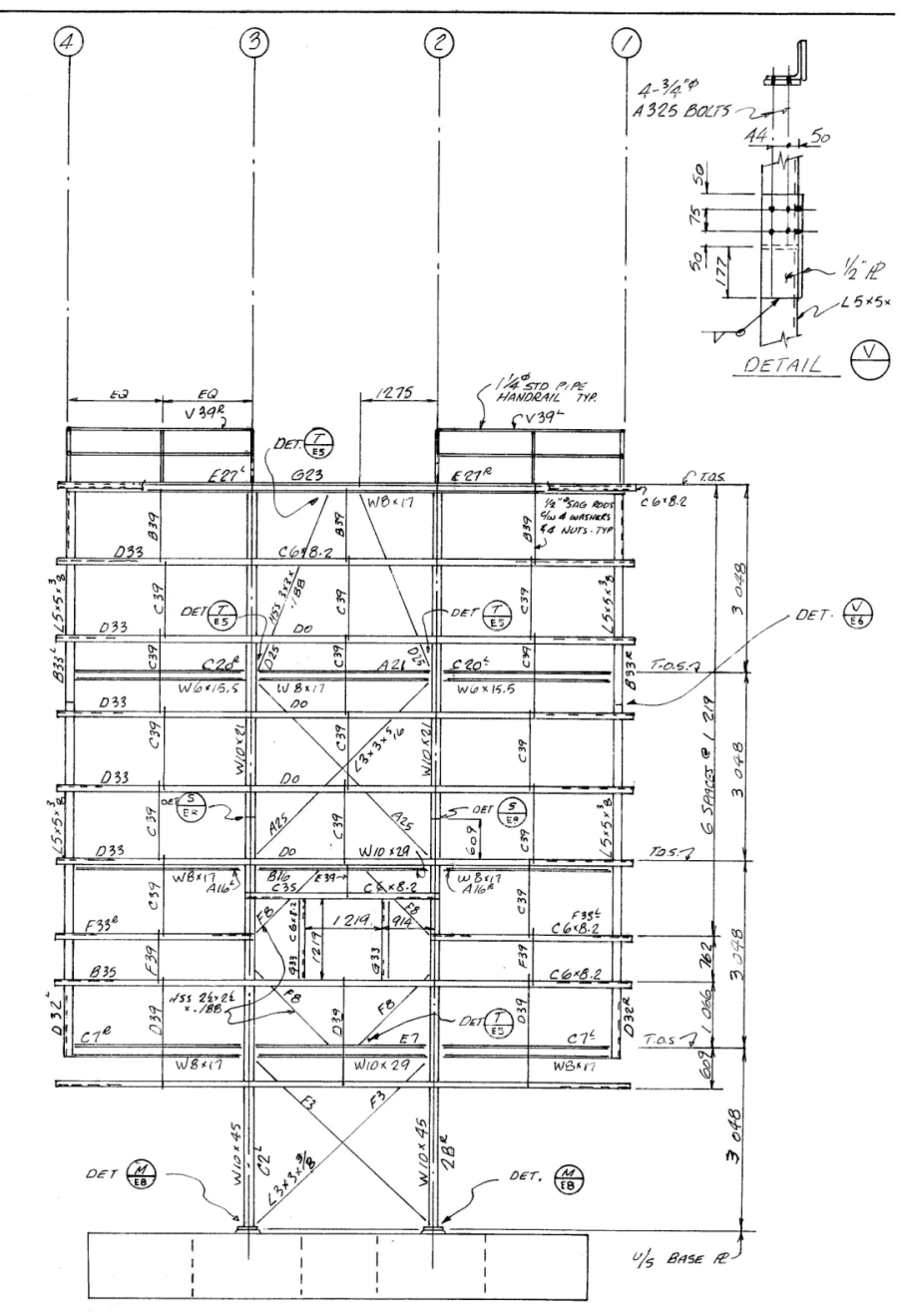

Figure 2: An extract from one of the technical plans

The first part of the task requires that the group calculates the total weight of the structure to be lifted (that is, the sum of the weights of the four beams). Beams of this kind are labelled with two pieces of information: their depth and their mass/weight per metre or foot, depending on whether 
metric or imperial measures are being used. For example, in this task one of the beams ' $W$ ' is 10 by 21 indicating a depth of 10 inches, and a weight of 21 pounds per foot. On a plan this would be written simply as 'W10 x 21'. However, what makes the task more complex is the fact that on the set of plans, not all the measurements and specifications are in imperial units. Some of the eight drawings are solely labelled in metric, whilst others actually mix imperial and metric units, depending on what it is that is being labelled. This is not an uncommon practice in the workplace, and thus it is necessary that apprentices become familiar with using both systems of measurement, and are able to move flexibly between the two. For example, on one of the diagrams, the specification of a beam is given in metric units W250 x 33. (Note this is not an exact conversion, but the nearest equivalent standard available metric sized beam). The question is further complicated as the length of the beams (on any of the diagrams) is always given in metric units. These lengths are either 3048 millimetres or 9144 millimetres, which in this case is simply a conversion from the imperial lengths of 10 and 30 feet (although this conversion is not printed on any of the plans). Thus, the apprentices are working in a mathematically complex environment, involving different units and representations that are mixed together in a variety of ways.

\section{Case study}

We join the apprentices at the start of the task, as they are looking at a number of the technical plans, locating the relevant beams on these and determining their specifications in order to calculate their weights.

Mike: It's a $W 10$ by 21. It's right here (pointing to a drawing of a beam on one of the pages of drawings where the specifications are in imperial units).

Joe: It's not what it says here partner (pointing to the same beam on a different plan where metric units are used).

Mike: Yeah, I know. Maybe that's $f . . . . . g$ metric or something? I don't know. Andy: $W 250$ by 33? (reading from the same page as Joe)

They begin by working with the drawn elevations, extracting the mathematical information contained on them that will be necessary for the calculation of the weight of the beam. They understand how to read the plans, and they are able to locate the correct beam and its specification from a complex diagram like Figure 2. However, Mike and Joe are using two different diagrams; one is a plan view (the structure from above), the other a cross-sectional elevation of the structure. Because the first of these gives a metric specification and the second an imperial, they become concerned about what they are working with. Mike has found the beam specification in 
imperial units, whilst Joe has it in metric. Although Mike recognises that this might be the case, he is not confident, or happy to just assume this is the case. The apprentices have an understanding of the visual representation of the task, and of how to use the diagrams to locate and extract appropriate mathematical information.

Mike: There's no way that's 250 inches deep. Its way easier if you ...

Joe: That's mills (millimetres). Teah.

Mike: Its way easier if we do it with inches. It's a W 10 by 21.

The comment by Mike 'There's no way that's 250 inches deep' illustrates how he is able to use his understanding of the task as an actual workplace job to reflect on the value they have read from the diagram. This is crucial for them being able to make sense of what they are doing. It is Mike's knowledge and understanding of how inappropriate a beam with a depth of two hundred and fifty inches would be, gained from his experience in the field, that instantly alerts him that something is wrong with the number as an imperial measure. For Mike the number has a meaning, it is more than an abstract object to be operated on - he is drawing on an image of a real beam and of what an appropriate depth should be, and is using this to inform his mathematical thinking. He now proceeds to try and find the total length of the beam from the diagram.

Joe: Okay. See its right there?

Mike: I'm just trying to find out how long it is. (pause). All I need is one measurement. Maybe it's 3,048 (reading a length from the plan).

Andy: For what?

(pause and mumbling from all three apprentices. Joe and Mike are looking at the drawing.)

Andy: That's what our centimetres will be, 3048.

Mike: You think so? Oh yeah, it will. It will be, 3,048. We know how long it is. Andy: I already got that (laughs).

Mike: Well. That's what we were after.

Here they return to the diagrams, and are now looking for the stated length of the beam. They locate the correct dimension, 3,048, though they think this is centimetres rather than millimetres. As noted earlier, this is a metric dimension on the page where the beam specifications are given in imperial units. There is a slight sense of them not being sure about this measurement, but they are confident that they have the correct information, again showing an ability to use the diagrams and to understand what the 
numbers on these mean. As noted, 3,048 millimetres is equivalent to ten feet in imperial units, and has resulted from the conversion of this to metric before adding to the diagram. Again, this illustrates how measurement is a messy system in these workplace environments, unlike the structured setting of school mathematics.

Joe: So 21 times 348 (working on calculator). You already got this down don't you? (talking to Andy) equals? Is that what you got? (Asking Andy).

Andy: Yeah (he sounds uncertain)

Joe: In mills?

Andy: In mills. That's f.....g

Joe: Sixty-four (He has actually calculated 3,048 x 21)

Andy: Sixty-four thousand. So it would be 64 .

Joe: That's not right.

Andy: Sixty-four?

Joe: Kilograms?

Having found the required specifications Joe now begins to calculate the weight of the beam. He knows the calculation to perform and obtains the correct answer. On seeing that the answer is 64,000, they decide this must mean a weight of 64 kilograms, a more likely weight for a beam than 64,000 kilograms. Again, here it is their knowledge of workplace practice and of the actual weight of real beams that informs this, rather than any mathematical rule. However, the mistake here is that they have incorrectly chosen to multiply a metric length by the pounds per foot specification, 21, which has given the wrong answer.

Andy: Kilograms. Yeah. (pause). That can't be right though. We did something wrong. Those beams ain't a hundred pounds.

Andy is able to bring his understandings of actually working with beams into play here saying 'That can't be right though. We did something wrong. Those beams ain't a hundred pounds'. This is a particularly important and powerful statement. He is able to not only think practically about the question as an actual task, but also is mathematically able to approximately convert the calculated weight into an imperial equivalent (albeit a rather inaccurate conversion). Without having a working knowledge of beams then it would perhaps be unlikely that they would have a sense of the previous answer being incorrect. 
Mike: Well, you have to do it the metric way. You can't times anything by 40.8. (Pause)

Joe: No, I'm not. I'm just timesing it by the weight per kilogram which is 21 .

Mike: Oh yeah.

Andy: Is that per metre?

Mike: No, that's per foot.

Andy: Yeah, we're doing metres though.

Mike: We got to change something around before we do that.

Andy: Because if we're changing that. No...

Mike: Yeah, yeah yeah. This is per foot.

Although all three apprentices recognise now that the calculation is incorrect, they are not instantly able to determine what to do instead. However, Mike and Andy use their understandings of the mathematical relations involved to realise that they 'need to change something around'. They understand the notions of pounds per foot and kilograms per metre, that these have different values and thus some conversion may be necessary. There is a sense of reasoning taking place here, of the apprentices understanding what they are trying to accomplish, and how to use mathematics in this process. They do not simply reach for a formula, nor seek help from the instructor, but neither do they use some informal method.

Andy: This one that you had over here (indicating the other plan) the 350 and the 250 times 33, that would be the millimetres.

Mike: Yeah.

Joe: Teah, you're right.

Mike: That can't be 250 by 33.

Andy: That's just the...

Mike: Oh yeah, 33 kilograms per?

Andy realises that they don't actually need to convert from imperial to metric, but instead could simply use the metric specification offered on the other diagram, and Mike and Joe agree with this. Mike knows this specification is in kilograms, but is not sure 'per what'. It should be noted that no units are printed on the diagram, so the beam is simply labelled as W250x33.

Andy: Per?

Mike: Per metre. (They both nod). Okay, yeah. We're happening now. Do it like this. Times it by 33. 
Andy: Thirty-three kilograms

Mike: Thirty-three kilograms per metre.

Mike is clear about the mathematics to use here. Now that he realises they are working with metric measurements, he knows quickly that all that is required is to multiply the length by the weight per metre, though it has taken him a moment to be sure of this. Interestingly, he even corrects Andy who perhaps is not as confident with exactly what the 33 means here. Mike is precise and accurate with his statement and again there is a sense of him understanding the mathematics he is using, and not merely applying a memorised formula. Sarah, a visiting tutor to the session, intervenes here to ask how they knew that the specification of the beam was in metric units.

Sarah: How do you know that?

Mike: Just because if the beam was 250 inches deep it would be a really, really big beam and we don't have any of those.

Mike justifies his thinking by drawing on his knowledge of actual beams, of what sizes they come in on the job. He knows that a beam with a depth of 250 inches is not realistic. Again, it is this facility to situate the mathematics within the real workplace context that allows him to make sense of his choice of numbers and subsequent calculation.

Joe: (completing the calculation while Mike talks to Sarah) Three zero forty-eight is the length?

Andy: Yeah.

(Joe continues to work on the calculator)

Andy: One hundred point five eight kilograms?

Joe: Tep. $^{-}$

Joe is able to correctly complete the calculation with an answer of 100.58 kilograms, and they agree that this is now the weight of the beam in kilograms. Although he does not verbalise it here, he has also converted the weight into kilograms, as the initial calculation would give the answer in grams (due to the use of millimetres rather than metres for the length). Although we do not see how he does this, again it seems that he has an awareness that a beam with a weight of one hundred kilograms is reasonable whereas one with a weight of 1,000 kilograms would not be. 
Andy: See that makes a little more sense.

Joe: Multiply two point two. Two hundred and twenty one pounds, that's more like it.

Andy: That's a little more like it.

Having got what they are confident is a correct answer, they still do not simply accept this, although they seem happy with their use of mathematical operations. Instead, they choose to check this answer (which is in metric) by converting it to imperial units, as the weight in pounds has a greater practical meaning for them. Joe and Andy agree that a weight of 221 pounds is 'a little more like it', thus validating their calculated answer in the context of the actual task, and of the size of beams involved. Joe knows what a beam should weigh, and that this is an appropriate specification. They are thus confident in their use of mathematics, and in the correctness of their answer, through drawing on understandings developed from the workplace.

Whilst it is true here that the apprentices could have immediately found the weight in pounds by recognising that 3,048 centimetres was the same as ten feet, and simply multiplying this by 21 , there is nothing in the diagrams to indicate this - nor any reason for them to notice this. What is striking though, both in the transcript extracts offered here, and in the whole session, of which these form a part, is the commitment of the students to the completion of the task, and of ensuring their answers are not merely mathematically correct, but make sense in the context of actually erecting the construction. They are not deterred by the complexity of the diagrams, nor that the required information and mathematical operations are not immediately obvious. They see problem solving of this kind as a natural part of their career choice, and of getting the job done.

\section{Flexible mathematical understanding in workplace training}

Mike, Andy and Joe move continually between three different ways of thinking mathematically and demonstrate a flexible understanding of the mathematics involved in the task, and of how to work with this in a meaningful way. Firstly, they are able to make sense of and work with the mathematics of the task, as embedded in the complex set of plans they are working from. Secondly, they understand and confidently use the mathematical operations required by the task - what to multiply together, why, how to convert units and so on. Thirdly, they understand what their mathematical answers actually mean in the context of the task, and the appropriateness of these for the beam construction they are working with. 
What we suggest is important is the way that the three apprentices are able to find the solution to the task through bringing these different forms of understandings together as they work. This facility to work with mathematics in such a fluid and flexible way suggests that they do not see more formal mathematical operations as distinct from the context of the task, but instead, as embedded within it. Their knowledge of actual beams informs their reading of appropriate specifications from the complex plans, and also the correctness of their answers. They do not resort to the simple use of a memorised formula for the conversion of units, nor do they use some informal ad-hoc method that is often the case in the workplace. Instead they use standard mathematical operations purposefully, with an understanding of what these will achieve and why. When an answer does not seem correct, they look to the workplace context to help consider why.

In observing the ways that Andy, Joe and Mike work, we would suggest that what is seen is not a process of transfer - that is 'a relatively passive "carrying over" and deployment of learning from one situation to another once learners recognize the "similarity" between those situations' (Carraher and Schliemann 2002:19). Instead we observe what Evans terms 'translation' wherein 'a making of meaning across discourses' (2002:223), in this case those of mathematics and workplace practice, is occurring. The three apprentices are simultaneously able to operate in the domain of mathematical operations and also that of the workplace, and to see the task they are working on as simultaneously drawing on elements from both sets of practices. This flexible understanding is similar to what Carraher and Schliemann talk of as an 'active accommodation of knowledge to the demands of the situation' in which the apprentices have 'not simply unloaded a prior solution from their storehouse of knowledge' but instead have 'crafted it on the spot, adjusting and adapting their prior knowledge in the process' (Carraher and Schliemann 2002:19). This facility to build or craft a powerful and dynamic understanding, that recognises the relationship between formal mathematical operations, the representation of mathematics in the task posed, and the use of mathematics in the situation context, is what enables Andy, Joe and Mike to be successful in the completion of the task, and to understand why their answer is appropriate and useful. For settings such as construction sites and workplaces, such an understanding and awareness is not merely desirable, but essential. As noted by Martin, LaCroix and Fownes 'in the school classroom, an incorrect answer will likely result in nothing more than a mark on a piece of paper, whereas in the workplace there are real costs associated with such errors' (2005:23). On a building site involving large constructions, such costs may be human, as well as financial. For example, the choice of an incorrect size of choker could lead to expensive materials being dropped, or to a crane tipping over, potentially causing injury or death. 
It is beyond the scope of this paper to consider what aspects of the learning experiences of Andy, Joe and Mike might have played a significant part in the development of such a flexible way of thinking and working. However, clearly their training allowed and encouraged them to make dynamic connections between what they learned whilst working on actual construction sites and what they learned in the trades training classroom. All three apprentices are able to make sense of the mathematics they know and use, and, perhaps more importantly, they are confident in their understanding and see it as sufficient to be able to complete complex tasks of the kind discussed here. In the field of adult mathematical learning, where it is often the struggles of learners that are reported (eg. Gal 2002, Ingeleton and O'Regan 2002) then the example of Andy, Joe and Mike is both hopeful and exciting and suggests that adults in apprenticeship training programs can be both successful construction workers and successful mathematicians.

\section{Acknowledgements}

The research reported in this paper is supported by the Social Science and Humanities Research Council of Canada, (SSHRG) through Grants \#831-2002-0005 and \#501-2002-005. We acknowledge the assistance of the British Columbia Institute of Technology, the Ironworkers Union Local 97 and the course instructors. We would also like to thank Andy, Joe and Mike for their willingness to be involved in the study.

\section{References}

Carraher, David W and Schliemann, Analucia D (2002) The Transfer Dilemma, The Fournal of the Learning Sciences, vol 11, no 1, pp 1-24.

Evans, Jeff (2000) Adults' Mathematical Thinking and Emotions - A study of numerate practices, Routledge Falmer, London.

Gal, Iddo (2002) Dispositional Aspects of Coping with Interpretive

Numeracy Tasks, Literacy and Numeracy Studies, vol 11, no 9, pp 47-62.

Ingleton, Christine and O'Regan, Kerry (2002) Recounting Mathematical

Experiences: Emotions in mathematics learning, Literacy and Numeracy Studies, vol 11, no 9, pp 95-108.

Kieren, Thomas E, Pirie, Susan E.B and Gordon-Galvert, Lynn (1999)

Growing Minds, Growing Mathematical Understanding:

Mathematical understanding, abstraction and interaction, in Burton,

Leone, ed, Learning Mathematics: From hierarchies to networks, Falmer

Press, London, pp 209-231.

Lave, Jean (1988) Cognition in Practice, Cambridge University Press, Cambridge. 
Lerman, Stephen (1999) Culturally Situated Knowledge, in Burton, Leone, ed, Learning Mathematics: From Hierarchies to Networks, Falmer Press, London, pp 93-107.

Martin, Lyndon C, LaCroix, Lionel and Fownes, Lynda (2005) Folding Back and the Growth of Mathematical Understanding in Workplace Training, Adults Learning Mathematics, vol 1, no 1, pp 19-35.

Noss, Richard, Hoyles, Celia, and Pozzi, Stefano (2000) Working Knowledge: Mathematics in Use, in Bessot, Annie and Ridgway, David, eds, Education for Mathematics in the Workplace, Kluwer Academic Publishers, Dordrecht, Netherlands, pp 17-36.

Nunes, Terezinha, Schliemann, Analucia D, and Carraher, David W (1993) Street Mathematics and School Mathematics, Cambridge University Press, Cambridge.

Pirie, Susan E B and Kieren, Thomas E (1994) Growth in Mathematical Understanding: How can we characterise it and how can we represent it? Educational Studies in Mathematics, vol 26, pp 165-190.

Pozzi, Stefano, Noss, Richard, and Hoyles, Celia (1998) Tools in Practice, Mathematics in Use, Educational Studies in Mathematics, vol 36, pp 105122.

Wedege, Tina (2002) 'Mathematics - That's what I can't do': People's affective and social relationship with mathematics, Literacy and Numeracy Studies, vol 11, no 9, pp 63-78. 
